\title{
Metacognitive processes in the self-regulation of performance in elite endurance runners
}

Brick, N., Maclntyre, T., \& Campbell, M. (2015). Metacognitive processes in the self-regulation of performance in elite endurance runners. Psychology of Sport and Exercise, 19, 1-9.

https://doi.org/10.1016/j.psychsport.2015.02.003

Link to publication record in Ulster University Research Portal

\section{Published in:}

Psychology of Sport and Exercise

Publication Status:

Published (in print/issue): 01/07/2015

DOI:

10.1016/j.psychsport.2015.02.003

\section{Document Version}

Author Accepted version

\section{General rights}

Copyright for the publications made accessible via Ulster University's Research Portal is retained by the author(s) and / or other copyright owners and it is a condition of accessing these publications that users recognise and abide by the legal requirements associated with these rights.

\section{Take down policy}

The Research Portal is Ulster University's institutional repository that provides access to Ulster's research outputs. Every effort has been made to ensure that content in the Research Portal does not infringe any person's rights, or applicable UK laws. If you discover content in the Research Portal that you believe breaches copyright or violates any law, please contact pure-support@ulster.ac.uk. 


\section{Metacognitive processes in the self-regulation of performance in elite endurance runners}

Article in Psychology of Sport and Exercise · February 2015

DOI: 10.1016/j.psychsport.2015.02.003

CITATIONS

7

3 authors, including:

\section{Tadhg Macintyre}

University of Limerick

91 PUBLICATIONS 399 CITATIONS

SEE PROFILE
READS

Some of the authors of this publication are also working on these related projects:

Go Green Ex: "GO GREEN EX Cubed” Going Outdoors: Gathering Research Evidence on ENvironment: 


\section{Accepted Manuscript}

Metacognitive processes in the self-regulation of performance in elite endurance runners

Noel Brick, Tadhg Maclntyre, Mark Campbell

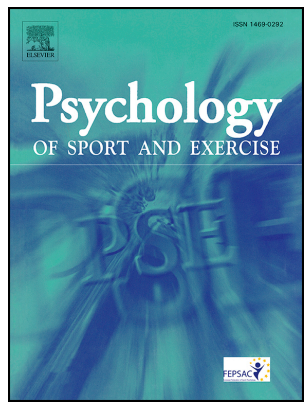

PII: S1469-0292(15)00010-2

DOI: $\quad$ 10.1016/j.psychsport.2015.02.003

Reference: PSYSPO 975

To appear in: Psychology of Sport \& Exercise

Received Date: 14 November 2014

Revised Date: 20 January 2015

Accepted Date: 17 February 2015

Please cite this article as: Brick, N., Maclntyre, T., Campbell, M., Metacognitive processes in the selfregulation of performance in elite endurance runners, Psychology of Sport \& Exercise (2015), doi: 10.1016/j.psychsport.2015.02.003.

This is a PDF file of an unedited manuscript that has been accepted for publication. As a service to our customers we are providing this early version of the manuscript. The manuscript will undergo copyediting, typesetting, and review of the resulting proof before it is published in its final form. Please note that during the production process errors may be discovered which could affect the content, and all legal disclaimers that apply to the journal pertain. 
1

2

3

4

5

6

7 Department of Physical Education and Sport Sciences, University of Limerick, Limerick, 8 Ireland

9

10

11

Address:

12

13 Tele:

14

E-mail:
Noel Brick, Tadhg MacIntyre, \& Mark Campbell runners

Metacognitive processes in the self-regulation of performance in elite endurance

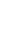
9

Corresponding Author: Noel Brick

15

16 
1

2

3

4

5

6

7

Metacognitive processes in the self-regulation of performance in elite endurance

8

runners

9

10 


\section{Abstract}

2 Objective: This study sought to investigate the dynamics of attentional focus and cognitive

3 control during endurance activity from a metacognitive perspective. The study also intended

4 to examine the situational factors which may influence cognitive strategy use by elite

5 endurance runners.

6 Design: Semi-structured qualitative interviews were utilised.

7 Method: Ten elite-level endurance runners were interviewed to explore retrospectively their 8 attentional focus and cognitive strategy use during endurance running.

9 Results: The findings revealed that metacognitive strategies such as planning, monitoring, reviewing and evaluating, and metacognitive experiences were fundamental to cognitive control and cognitive strategy use in elite endurance runners. The findings also added to the array of active self-regulatory strategies previously reported in the literature.

Conclusions: These results suggest that metacognitive processes are central to effective cognitive control in elite endurance athletes during running. The findings allowed for the development of an integrative metacognitive framework, which incorporates dimensions of attentional focus. This model may better represent the processes which underpin cognitive control and determine cognitive strategy use in elite athletes during endurance running.

\section{Keywords}

Metacognition; cognitive strategy; attentional focus; self-regulation; endurance exercise 


\section{Introduction}

2 The study of attentional focus in endurance activity has operated on a largely atheoretical

3 basis since its inception almost four decades ago. While subsequent research has progressed

4 our understanding of how cognitions - both deliberate and spontaneous - impact endurance

5 performance (see Brick, MacIntyre, \& Campbell, 2014 for a detailed review), the need for a

6 comprehensive conceptual framework still exists. Recent proposals include a social-cognitive

7 perspective (Tenenbaum, 2001), Leventhal and Everhart's (1979) parallel processing model

8 of pain (Brewer \& Buman, 2006), and a mindfulness approach (Salmon, Hanneman, \&

9 Harwood, 2010).

The above approaches allude to potential mechanisms to explain how specific

cognitions may allow endurance performers better tolerate exertional discomfort. For

example, Tenenbaum's (2001) social-cognitive perspective considers the multidimensional

nature of effort tolerance and perceived exertion. Similarly, Brewer and Buman's (2006)

application of the parallel processing model provides an insight on how attentional foci may

alter pain perception. Some issues remain unaddressed, however. Brewer and Buman (2006),

for example, expressed a need to clarify how individuals develop schemata, or cognitive

structures developed from previous pain experiences, to accurately evaluate exertional signals during exercise. Concomitantly, we further highlight the need for a framework to illustrate how endurance performers control cognitive activity to optimise performance. athletic performance from the perspective of cognitive sport psychology (Moran, 2009, 2012). Theoretical approaches, such as grounded cognition recognise the interaction between perception, action, the body, and the environment during goal achievement (e.g., Barsalou, 2008). When these interactions pose a significant challenge, such as during effortful 
1

2

endurance running, a high level of cognitive control, or the ability to 'regulate, coordinate, and sequence thoughts and actions in accordance with internally maintained behavioural goals' (Braver, 2012; p. 106) should be important. In such situations, a focus of attention which best facilitates performance may be considered an imperative to competitive success.

To emphasise the significance of cognitive control, much research evidence supports the contention that attentional focus impacts endurance performance (e.g., Brick et al., 2014; Schücker, Knopf, Strauss, \& Hagemann, 2014). Amongst elite performers, task-relevant, selfregulatory cognitive strategies have been shown to facilitate performance improvement, while distractive thoughts may result in non-optimal pacing (e.g., Clingman \& Hilliard, 1990; Rushall \& Shewchuk, 1989). What is less clear is when, or why endurance athletes engage specific attentional strategies. It has been suggested that elite performers employ cognitive strategies depending on circumstance and need (e.g., Moran, 1996). However, little is understood about the determinants of cognitive strategy use amongst elite endurance athletes.

One framework which may help to address these conceptual issues is the metacognitive approach. Metacognition has been defined as an individual's insight into, and control over their own mental processes (Flavell, 1979), and is a key sub-process of, and essential to effective self-regulation (Tarricone, 2011). Efklides (2006) describes metacognition as a model of cognition, acting at a meta-level, and related to cognition through monitoring and control functions. Thus, meta-cognition implies two (or more) processes, one concerning cognitions of external objects (i.e. object-level cognition), and a second, the meta-level, concerning cognitions of object-level cognitions (Nelson, 1996). Metacognitive process include metacognitive strategies (or metacognitive skills) such as planning and monitoring, and metacognitive experiences (Efklides, 2006; Tarricone, 2011). Based on monitoring processes, metacognitive experiences allow for concurrent, or 
1 'on-line' monitoring during task performance. They include metacognitive feelings, which

2 inform the individual about task performance in the form of a feeling, such as feelings of

3 difficulty, and tend to be implicit in nature (Efklides, 2006). Alternatively, metacognitive

4 judgements and estimates, such as judgement of solution correctness, are made by the

5 individual, and may be the result of both implicit, non-analytic processes, and explicit,

6 analytic processes (Efklides, 2006). Collectively, awareness of metacognitive experiences, in

7 conjunction with performance, forms a representation of the task, or the context (Efklides,

8 2014). In turn, these metacognitive representations provide input for conscious, deliberate

9 regulation and control of cognition via cognitive, or metacognitive strategies (Efklides,

10 2014). Applied to the current study of endurance running, metacognitive representations may

11 indicate the perceived difficulty of a running task, for example, and provide the impetus for the initiation of an appropriate cognitive strategy to control attentional focus.

A metacognitive framework has the potential to enhance our understanding of selfregulation and cognitive control during endurance activity. Precedent for this contention can be found in physical activity (e.g., Settanni, Magistro, \& Rabaglietti, 2012), and pain management (e.g., Yoshida et al., 2012) settings, for example. Metacognition has also been considered a distinguishing feature of expert performance in the sporting domain (MacIntyre, Igou, Campbell, Moran, \& Matthews, 2014). However, few researchers have specifically employed a metacognitive perspective to investigate attentional dynamics in endurance activity. Only Nietfeld (2003) highlighted the significance of metacognitive monitoring and strategy use during endurance running. Consequently, the role of metacognitive processes in controlling cognition during endurance performance has yet to be fully explored. metacognitive approach to better understand the influences on, and dynamics of attentional 
1 focus and cognitive control during endurance activity. The emphasis was on elite endurance

2 runners, to determine cognitive strategy use during both competition and endurance training.

3 Employing this strength-based approach, high-ability participants were deliberately recruited

4 on the basis of their expertise and experience in endurance activity, and potential for highly

5 developed cognitive abilities (e.g., MacIntyre, Moran, Collet, \& Guillot, 2013; MacIntyre et

6 al., 2014). Combined with a theory-driven analysis of cognitive activity, (i.e. metacognition),

7 the convergence of these approaches (MacIntyre et al, 2013) may advance our understanding

8 of attentional focus and cognitive control during endurance running. The second key aim of

9 the study was to more clearly illustrate the situational factors which may influence the

10 attentional focus and cognitive strategy use by elite endurance runners.

Method

\section{Participants}

Elite endurance runners were purposefully sampled for the present study. Following institutional ethical approval, a recruitment email was sent to prospective athletes via the national endurance coach. Potential participants were also contacted via email. Inclusion criteria were that runners had competed internationally at senior-level running competition during their career and still ran competitively in events ranging from $3000 \mathrm{~m}$ to ultra-distance (e.g. 24-hour, $100 \mathrm{~km}$ ). The sampling procedure provided a total of 10 athletes who met these criteria and were willing to participate. Considering the idiographic aims of the study (e.g., Côté, Salmela, Baria, \& Russell, 1993), the sample size was considered appropriate to allow individual cases to be represented in the data, and for a sufficiently intensive analysis of each case to be conducted (Robinson, 2013). Employing a classification system proposed by Swann, Moran, and Piggott (2015), two of the athletes were classified as successful elite, and eight were classified as competitive elite. See Table 1 for participant demographics. 
1

2

4

5

6

7

8

\section{[INSERT TABLE 1 NEAR HERE]}

\section{Data Collection}

Pre-Interview information. Approximately one week prior to interview, each participant was emailed a pre-interview information sheet (see appendix 1). The purpose was to familiarise participants with the area of research, the procedures involved, and to clarify the purpose of the study (Wagstaff, Fletcher, \& Hanton, 2012).

Qualitative interview guide. Given the limited knowledge available on metacognitive activity during endurance running, a qualitative approach to data collection was considered best suited to this study. A semi-structured interview guide was developed based on a review of the attentional focus literature (see Brick et al., 2014), and on relevant accounts from the metacognition literature (e.g., Efklides, 2006; Tarricone, 2011). The format and structure of the guide derived from reviewing previous studies with an exploratory intent (e.g., Sarkar \& Fletcher, 2014; Wagstaff et al., 2012). Prior to the study, the interview guide was piloted with three endurance athletes, and was subsequently refined for clarity and content. The finalised guide (see appendix 2) consisted of six sections, and explored the athletes' mental preparation for running, their cognitive strategy use during running (both competition and training), the athletes' monitoring of attentional foci and cognitive strategy effectiveness, and how they acquired, developed, and refined the cognitive strategies used.

Interviews. Initial exploration required the athletes to retrospectively recount their attentional focus and cognitive strategy use during endurance running. Subsequently, participants were provided a list of attentional foci and cognitive strategies typically used by runners (see Brick et al., 2014). Participants were invited to discuss their use of both the attentional foci dimensions on this list, and any other strategies they might employ. Nine of the interviews were conducted face-to-face, while one interview was completed via 
telephone. All interviews were conducted by the first author, and each participant gave

written informed consent prior to commencement. The interviews lasted between 55 and 98 minutes $(M=75.5 \mathrm{~min}, S D=13.5)$. Each interview was digitally recorded and transcribed verbatim for subsequent analysis. Member checking was completed by returning transcripts to the interviewee within one week of interview to review for accuracy.

\section{Data Analysis}

Qualitative interview data. There are many differing methodological approaches to analysing qualitative data, including grounded theory, and discourse analysis (Vaismoradi, Turunen, \& Bondas, 2013). Given the exploratory nature of the present study, however, the most suitable approach was considered to be a content analysis (Green \& Thorogood, 2004). According to Elo and Kyngäs (2008), there are three phases to content analysis; preparation, organising, and reporting of the data. Following transcription of the interview, the first author initially immersed himself in the interview data. Because a metacognitive perspective was employed to analyse the interview transcripts, a deductive approach was considered the most suitable modality for initial data analysis (Elo \& Kyngäs, 2008). After further consideration, it was decided to analyse both manifest and latent content in the data, given that some metacognitive processes may be non-conscious in nature (Efklides, 2006). Units of analysis relevant to attentional focus and cognitive control during running included single words, sentences and more complete paragraphs.

To organise the data, a categorisation matrix was developed using both a conceptual framework of metacognition (Tarricone, 2011) and Efklides' (2006) facets of metacognition. The data was reviewed for content and coded for correspondence with these categories. Analysis was not constrained to the categories of the conceptual framework, however. As analysis of each transcript continued, and content emerged from the data, new categories and 
1

2

subcategories were created and defined, thus following the principles of inductive content analysis within a broader deductive analysis (Elo \& Kyngäs, 2008).

To check credibility, and to enhance the trustworthiness and quality of the analysis,

the researchers periodically discussed the emergent categories and reached agreement

through constructive debate (e.g., Sarkar \& Fletcher, 2014). To ensure reliability between the classification of raw data and the content of the transcripts, the researchers independently analysed the data using the categorisation matrix. A follow-up meeting took place to discuss the consistency of analysis and refine the matrix. Finally, a second reliability check was performed on the classification process. For this, an independent analyst analysed a random sample $(20 \%)$ of the transcripts. Following familiarisation with the classification system and subsequent analysis, further refinements were made to the categorisation matrix, after which greater than $80 \%$ agreement was reached with the independent analyst. With consensus reached, categories were established and the results were synthesised.

\section{Results}

The findings from the interview data were organised under two broad cognitive and metacognitive dimensions; Regulation of Cognition, and Metacognitive Experiences.

Presentation of the results will focus primarily on the dimensions that emerged from the data, and specifically on the categories and subcategories that either influenced, or resulted from the control of cognition during running. The findings are presented using quotations from the interviews to illustrate the metacognitive processes influencing cognitive control during running. The range of cognitive and metacognitive processes are presented fully in Figure 1.

\section{[INSERT FIGURE 1 NEAR HERE]}

\section{Regulation of Cognition}


2 for competition, and plan for training. The most frequently cited planning for competition subcategories were plan race tactics and pacing, plan race objectives, and plan other cognitive strategies, and both successful elite runners reported each of these processes. A minority of athletes discussed planning for training. Though most reported planning alone, some athletes planned race objectives (three athletes), and race tactics and pacing (two athletes) with their coach. Tactics and pacing for longer races, such as marathons, focused primarily on individuals' own performance. For shorter races, however, athletes were also apt to consider potential competitors, as one successful elite athlete recounted:

I'd be thinking about like who's in the race and so for international races you could, kind of, look at what races they ran previously and how they did and how their form is, and, ah, then I would be checking out the route of the race and the map of the race and be looking at that. And, ah, yea different like points in the race, whether it be like say cross-country... you'd usually go walk the course and decide, like, if you're going to put in any tactics and where you're going to make your moves, or if you're going to sit in and stuff.

Most athletes planned other cognitive strategy use (i.e. other than race objectives, tactics and pacing) by themselves or with their coach, while three athletes reported planning cognitive strategies with a psychologist. No athletes reported specifically planning cognitive strategy use before training, however. The following quote from one of the successful elite runners typifies an approach to planning cognitive strategy use before a race:

So, I'd have it planned before, and I haven't really had a race where I haven't been able to think what I want, bar things were going so bad it was just like, you know, 

your head wasn't in it as such like. That doesn't happen very often, but, ah, I'd have planned like I'm going to think about my breathing or do the posture checks or I'm going to have this song that I've been using in training anyway, you know.

While these results indicate the importance of planning, many aspects of competitive running cannot be planned for. To emphasise this point, athletes indicated that many cognitive strategies were implemented in reaction to situational events that occurred during running. As such, the importance of monitoring relevant information and responding in an appropriate manner was highlighted, and was the next category to emerge from the data.

Monitoring during running. Monitoring during running consisted of both internal sensory monitoring, and outward monitoring. The most frequently cited internal sensory monitoring subcategories were monitor bodily sensations, and monitor overall effort or feel. Bodily sensations monitored during running included exertional pain and muscular fatigue, breathing, thirst and nutritional needs, and body movement and form. Internal sensory monitoring was typically used for informational purposes to control cognition. For example, while many athletes reported awareness of exertional pain during running, this awareness was primarily used as a signal to engage an appropriate cognitive strategy. During competition, the purpose was to divert attentional focus from pain sensations and maintain performance. In contrast, during training exertional pain was used by some athletes $(40 \%)$ to monitor their response to the training load. Both contexts were epitomised by one marathon runner:

If you are hurting, and you are in pain ...it's part of the race, you expect that anyway, subconsciously you just push through it anyway. Whereas in training, it's something that you'd sometimes keep in check, because you wouldn't want to push through that 
to the same extent. You've got to keep in mind that you've got another couple of intervals to do, or that it's part of a long-term plan...

Monitoring overall effort and feel was predominantly used by athletes to gauge

running intensity and pacing. While eight runners reported monitoring overall effort and feel, many $(50 \%)$ of the athletes also recounted how they associated a feeling of effort with running pace during training, and this feeling was subsequently used to gauge running intensity. For example, one athlete reported about their marathon training:

I know what it should feel like... So if I'm doing... like a lot of my tempo runs were surprisingly easy... our tempo runs are like $6: 10$ or 6:20 pace, and I was targeting six minute miling [sic], ah, so, I feel absolutely fine at 6:10 pace like, you know.... So I know that feeling, so it's about the way I should feel during it...

The athletes reported using outward monitoring more often during competition than training, and frequently cited subcategories were monitor split-times for pacing, monitor other runners during racing, and monitor course/route/terrain. Perhaps unsurprisingly for competitive athletes, monitoring other runners during racing was important for pacing and tactical decisions. The need to monitor the running course and terrain was also important for pacing or tactical decisions, particularly for athletes who ran cross-country or trail courses.

Thus, the information athletes gleaned via internal sensory and outward monitoring appeared to play a pivotal role in cognitive control and the adoption of a suitable attentional focus to cope with the demands of the running task.

Controlling cognition during running. The importance of cognitive control by means of active self-regulatory strategies was emphasised by both the number of athletes reporting active self-regulatory strategy use, and by the range of idiosyncratic strategies 
1 revealed (see Figure 1). Active self-regulatory strategies recounted by each of the elite

endurance runners were pacing and tactical decisions, relaxation, and chunking distance or time. Often, active self-regulatory strategies were used in combination, as conveyed by one runner describing their cognitions over a half-marathon distance:

... and then you obviously want to focus on your running form really itself and making sure that you're trying to keep as relaxed as possible and just keep the same rhythm ticking over, and yea, keeping the breathing just as relaxed as possible as well. Yea, just try keep focused on everything you're doing and making sure that you're running at a pace that's being sustained for the 13 miles.

Active self-regulatory strategies served many distinct purposes. For example,

chunking distance or time was predominantly used to break down the perceived challenge of longer distance runs, or intense interval sessions and maintain a present moment focus. Furthermore, athletes attended to running technique when running was difficult (e.g., running uphill), as part of a periodic check, or during situations when fatigue, and a deterioration of movement efficiency may have been a concern. Typically, for running technique athletes would focus on task-relevant cues such as maintaining an efficient running 'form', using their arms, keeping elbows in, or hips high. Similarly, relaxation, self-talk and mantras (positive and motivational), and mindfulness were primarily used when athletes experienced greater exertional pain. Overall, active self-regulatory strategies were principally engaged when a need optimise performance or cope with increased physical discomfort was a priority.

Conversely, during easier, slower paced, or longer distance runs (e.g. training or ultradistance), active distraction/switching off was a more frequent attentional focus. In such circumstances, when the athlete felt comfortable, or performance was less of a concern, 
1

2

active distraction served to relax control over cognition, and allow the athlete engage in other thoughts. Using other people for distraction and conversing was also a recurrent distractive strategy during training or ultra-distance running. However, during intense racing or strenuous training the majority of athletes, including both successful elite runners, reported attempts to avoid involuntary distraction and stay focused. Overwhelmingly, involuntary distraction was associated with performance disruption, and typically avoided by engaging an active self-regulatory strategy. For example, counting was expressly used by two athletes to counter involuntary distraction and regain a more effective attentional focus. One competitive elite athlete runner did indicate an occasional need for others to interyene (e.g. a coach shouting instructions) when they became involuntarily distracted, however. The importance of controlling cognitive focus and avoiding involuntary distraction during racing was emphasised by one runner who recounted this experience over an $8 \mathrm{~km}$ cross-country race:

I went through the $2 \mathrm{k}$ and the $4 \mathrm{k}$ on the back of the leading group. Ah, and going into the third lap, I started falling off the leading group. And that... it was everything for me to stay attached, and it was only for there was a person there standing at that time, and suddenly I just lost a seconds concentration, and it was like, 'don't lose the concentration, concentrate now', and I covered the move, and...I finished second...in that race. But only for that split second, it meant everything for me. It was like down to, I'd say literally, two seconds worth of concentration like, 'cause if I had fallen off that group, I wouldn't have gotten back on the group, and that would have been it...

Overall, the elite endurance runners in the present sample reported a diverse range of cognitive strategies used to control attentional focus. These strategies were primarily acquired through experience, or from discussions with significant others. The following section deals with reviewing and evaluating processes that emerged from the interview data. 
of athletes also reported reviewing and evaluating with others, such as with a coach, or a psychologist. Reviewing and evaluating by self after running included the subcategories of evaluate cognitive strategies and performance, acquire cognitive strategies through experience, and eliminate ineffective cognitive strategies. Subsequently, many cognitive strategies were acquired through experience and further developed and refined, a processes characterised by an elite athlete competing in 24-hour events:

strategies as a result of reviewing and evaluating. These findings highlight the importance of reviewing cognitive strategies and performance to develop a bespoke range of strategies for future use. In addition, evaluations were often based on metacognitive experiences, and these were the second broad dimension to emerge from the data. 
Metacognitive feelings. The categories of metacognitive feelings that emerged from the data were feeling of knowing, feeling of difficulty, feeling of confidence, and feeling of

3 familiarity. Metacognitive feelings were a product of both internal sensory monitoring and outward monitoring during running. The metacognitive feelings which tended to mediate cognitive control were feeling of knowing, and feeling of difficulty.

In terms of feeling of knowing, each performer reported knowing when to apply a cognitive strategy. Only one competitive elite runner reported a feeling of knowing one does not know a cognitive strategy to apply, and alluded to specific competitive race scenarios where they experienced direct, 'head-to-head' racing with other competitors. Athletes did not always explicitly report a feeling of knowing, but rather described contexts where they would employ particular cognitive strategies. Similarly, feeling of difficulty was strongly associated with cognitive control during running, and athletes typically engaged an active self-regulatory strategy when running felt hard, or an active distraction strategy when running felt easy.

These interactions were exemplified by a marathon, and mountain running competitor: ...I suppose there's times when things are appropriate and when things are not, and some of them are like your emergency strategies... and others are, sort of, a lesser strategy. So like the thing where I say sometimes I would count or whatever, or think of a number in my head... generally you do that at a point where... you might be mildly uncomfortable, or you're ok, or it's fine.... But...the thing where you look at your band or you just have to accept, you do the pain acceptance thought in your head... that is more in a situation that's more... emergency 'cause you're in a lot of pain, you're really suffering quite a bit.

Thus, both feeling of knowing, and feeling of difficulty specifically acted as stimuli to adopt a suitable cognitive focus to cope with the subjective demands of a running task. 
Metacognitive judgements and estimates. The main categories of metacognitive

2

judgements and estimates that emerged were estimate of solution correctness, judgements about own capabilities, judgements about running performances, and estimate of effort. With regard to estimate of solution correctness, the majority of athletes, including both successful elites, recounted judgments of effective cognitive strategies, and judgments of ineffective attentional focus. Active self-regulatory strategies were predominantly judged as effective, however. Subsequently, athletes reported how these strategies benefited running performance, as typified in the following quote by one competitor:

So, the more tight you are; your stride is short, or everything, your breathing, everything. So, the minute I relax and I drop my arms, my elbows are in and my knees are high, my stride automatically lengthens.... So, already I'm on a better flow...

Distractive thoughts were judged equally as effective or ineffective, depending on the running context and circumstantial needs. Involuntary distraction was unanimously judged as ineffective, however, and considered to have a negative impact on performance.

Although more athletes reported positive judgements about their own capabilities, beliefs about own attributes, and beliefs about own limitations influenced both planned, and self-regulatory pacing and tactical decisions prior to, and during running. Conversely, judgements about running performances, and estimate of effort were strongly related to reviewing and evaluating after running. In particular, while satisfaction with own performance was often reported following races where cognitive strategies worked well, dissatisfaction with own performance followed accounts of less successful races, or cognitive foci that did not work well. Similarly, feeling tired because of competition or training load was often associated with an adjustment to training plans, or an understanding by the athlete that such feelings were an inevitable consequence of their current training cycle. 
2 The findings of the present investigation indicate that metacognitive processes may be

3 fundamental to effective cognitive control during running in elite endurance runners. The

4 data also supports the contention that metacognition underpins expertise in both training and

5 competitive sporting settings (MacIntyre et al., 2014). Metacognitive processes, such as

6 planning, monitoring, reviewing and evaluating, and metacognitive experiences were central

7 to the adoption and initiation of cognitive strategies during running. The present study

8 highlights the role of metacognitive monitoring and control functions to cognitive regulation

9 (Efklides, 2014) in the context of endurance running.

In terms of monitoring activities, the athletes in this study appeared to have

established, through experience, a means of prioritising sensorimotor inputs to optimise

running performance. Periodic monitoring of internal states (e.g. exertional pain) and the outward environment (e.g. other runners) often generated metacognitive feelings, such as running feeling hard, or knowing when to apply a cognitive strategy, for example. In turn, these metacognitive representations exerted control over cognition (Efklides, 2006). These data suggest that the present elite endurance runners predominantly attended to the informational aspect of sensory stimuli, and used this information to adopt a focus of attention appropriate to the context.

Controlling cognition on the basis of monitoring processes might be considered a form of reactive (Braver, 2012), bottom-up (Buschman \& Miller, 2007), or stimulus driven (e.g., Corbetta \& Shulman, 2002) attentional control. Braver (2012) suggests that reactive cognitive control may have the advantage of efficiency and be less demanding on cognitive resources. Furthermore, linked with the parallel processing model of pain (Leventhal \&

24 Everhart, 1979), metacognitive representations may explain how athletes develop schemata to 
1

2

3

5

6

7

8

9

appraise exertional signals during running. Via metacognitive strategies and experiences, these schemata may allow experienced runners to appraise pain signals more accurately (Brewer \& Buman, 2006) and adopt an appropriate cognitive focus as a result.

Alongside reactive control, evidence for proactive cognitive control (Braver, 2012) also emerged. Athletes often reported employing metacognitive skills such as planning cognitive strategies prior to competitive running and it is noteworthy that both successful elite runners engaged in planning pre-competition. While proactive control may be more demanding of cognitive resources, potentially deleterious interference from both internal and external distractors may be minimised as a result (Braver, 2012). To assist proactive control, some athletes also reported planning with significant others, such as coaches and psychologists. This form of social metacognition may be considered as metacognition at a meta-meta-level (e.g., Efkildes, 2014) and allow for communication of metacognitive information (Shea et al., 2014). Discussions during instances of planning and evaluation may have developed athletes' abilities to interpret metacognitive representations, for example, and moderate strategy selection and subsequent cognitive control during running.

The range of cognitive strategies reported by the elite endurance runners was diverse. The findings add substantially to the array of active self-regulatory strategies previously reported (Brick et al., 2014). Crucially, however, the present findings also add clarity as to when, and why the athletes initiated specific cognitive strategies. All athletes reported focusing on pacing and tactical decisions during competition, for example, which were often informed by metacognitive representations resulting from outward environmental monitoring activities. For example, pacing and tactical decisions during running were often preceded by a metacognitive feeling of confidence, and specifically a belief in one's ability to meet the task demands. Regulating performance, based on task-relevant environmental monitoring, has 
1

2

previously been shown to improve competitive endurance performance (e.g., Williams et al., in press). More importantly, in the present discussion, controlling action based on the outcome of metacognitive processes highlights the role of metacognitive activity in movement planning, guidance, and execution (e.g., Augustyn \& Rosenbaum, 2008).

Knowing when to apply a cognitive strategy was predominantly influenced by task context and demands (e.g., Efklides, 2014; Tarricone, 2011). For example, when running felt hard (metacognitive feeling of difficulty), self-regulatory strategies such as relaxation, positive and motivational self-talk, mindfulness, and a focus on running technique were frequently initiated. Athletes also repeatedly judged these strategies as effective, and research evidence reinforces the beneficial impact of these self-regulatory strategies on both endurance performance (e.g., Blanchfield, Hardy, de Morree, Staino, \& Marcora, 2014; Rushall \& Shewchuk, 1989) and cognitive function (e.g., Hasse et al., 2014). The finding that athletes used mindfulness techniques, alongside other cognitive strategies during running suggests that mindfulness might be considered an active self-regulatory strategy, rather than a conceptual framework within the attentional focus domain (e.g., Salmon et al., 2010).

Reported episodes of distraction further highlighted a tendency by the elite runners to adapt attentional focus based on contextual needs (e.g. Moran, 1996). Specifically, active distraction predominantly occurred when running tasks were longer (e.g. long training runs, or ultra-distance races), were relatively undemanding, and felt easier (metacognitive feeling of difficulty). Research on mind-wandering suggests that distractive thoughts may intensify in such contexts (e.g., Randall, Oswald, \& Beier, 2014), and can be useful to allow relief from boredom, for example (e.g., Mooneyham \& Schooler, 2013). However, when optimal performance was a priority, such as during shorter races, or intense training sessions, athletes reported avoiding involuntary distraction. In such circumstances, distraction was often judged 
1

2

3

4

5

6

7

8

9

as ineffective, and cognition assumed a form of conscious, top-down control (e.g., Buschman \& Miller, 2007; Corbetta \& Shulman, 2002), where processing of irrelevant information was attenuated in favour of a more appropriate attentional focus. It was noteworthy that one competitive elite reported not knowing a cognitive strategy to employ in specific, competitive racing situations, while another reported needing external assistance on occasion when they became involuntarily distracted. While neither successful elite athlete reported such issues, this may indicate that athletes of a lower performance standard may benefit from interventions to develop metacognitive skills and optimise self-regulatory abilities.

Finally, while contributing to cognitive control during running, metacognitive judgements and estimates also informed evaluative processes after running. Metacognitive judgements and estimates allow information on progress reach the level of conscious awareness (e.g., Efklides, 2014). Thus, judgements about running performances, or estimates of solution correctness, for example, were critical antecedents to the conscious review of running performances. As with planning, reviewing and evaluating were also performed both individually, and with significant others, once more implying supra-personal cognitive control, and metacognition both at a meta-, and at a meta-meta-level (e.g., Efkildes, 2014; Shea et al., 2014). These metacognitive processes allowed athletes adopt and refine those strategies which were effective, and eliminate those which were not.

The data indicate the potential utility of a metacognitive perspective to guide research activity in the attentional focus domain. Figure 2 provides a framework to illustrate the interactions between metacognitive process and the attentional focus dimensions suggested by Brick et al. (2014). According to this framework, athletes (and significant others) may (1) plan cognitive strategies, or what to monitor, prior to running. During running, monitoring processes (2) may directly, or via metacognitive feelings (3), form a metacognitive 
1 representation of the running task which, in turn, stimulates cognitive control and the adoption of an appropriate cognitive strategy (4). For example, internal sensory monitoring (e.g. increased exertional pain), and outward monitoring (e.g. of a competitor) may generate a metacognitive feeling (e.g. running feels hard). Awareness of this feeling, in conjunction with awareness of performance, forms a representation of the task which, in turn, stimulates the initiation of an appropriate cognitive strategy (e.g. to relax), and exert control over cognition.

\section{7 [INSERT FIGURE 2 NEAR HERE]}

Consequently, the athlete may make explicit metacognitive judgements or estimates

(5) regarding the (in) effectiveness of the cognitive strategy employed (e.g. estimate of

solution correctness). Depending on the outcome of this metacognitive judgement, alongside

continued monitoring of task performance, the athlete may choose to maintain their current

attentional focus, or adopt an alternative cognitive strategy. Following performance,

metacognitive judgements and estimates may further inform review and evaluation processes

(6). At this point, cognitive strategies may be further refined, or eliminated and, as a result, impact on metacognitive planning prior to future running activities.

The findings of the present study indicate that metacognitive strategies, such as

17 planning before running, and reviewing and evaluating after running influence attentional

18 focus and cognitive control during running. Further, metacognitive experiences, such as metacognitive feelings, and metacognitive judgements and estimates inform cognitive strategy use in elite endurance runners. This knowledge allows us to augment our understanding of psychological skills (e.g., MacIntyre et al., 2014; Moran, 1996) with an appreciation of when and why elite endurance runners initiate cognitive strategies during running. Integrated with the dimensions of attentional focus suggested by Brick et al. (2014), 
1 the present study highlights the utility of a metacognitive framework to advance our

2 understanding of attentional processes during endurance activity.

\section{References}

Augustyn, J. S., \& Rosenbaum, D. A. (2005). Metacognitive control of action: Preparation for aiming reflects knowledge of Fitts' Law. Psychonomic Bulletin and Review, 12, 911-916. http://dx.doi.org/10.3758/BF03196785

Barsalou, L. W. (2008). Grounded cognition. Annual Review of Psychology, 59, 617-645. http://dx.doi.org/10.1146/annurev.psych.59.103006.093639

Blanchfield, A. W., Hardy, J., de Morree, H. M., Staino, W., \& Marcora, S. M. (2014). Talking yourself out of exhaustion: The effects of self-talk on endurance performance. Medicine and Science in Sport and Exercise, 46, 998-1007. http://dx.doi.org/10.1249/MSS.0000000000000184

Braver, T. S. (2012). The variable nature of cognitive control: A dual mechanisms framework. Trends in Cognitive Sciences, 16, 106-113. http://dx.doi.org/10.1016/j.tics.2011.12.010

Brewer, B. W., \& Buman, M. P. (2006). Attentional focus and endurance performance: Review and theoretical integration. Kinesiologica Slovenica, 12, 82-97.

Brick, N., MacIntyre, T., \& Campbell, M. (2014). Attentional focus in endurance activity: New paradigms and future directions. International Review of Sport and Exercise Psychology, 7, 106-134. http://dx.doi.org/10.1080/1750984X.2014.885554

Buschman, T. J. \& Miller, E. K. (2007). Top-down versus bottom-up control of attention in the prefrontal and posterior parietal cortices, Science, 315, 1860-1862. http://dx.doi.org/10.1126/science.1138071 
1 Clingman, J. M., \& Hilliard, D. V. (1990). Race walkers quicken their pace by tuning in, not stepping out. The Sport Psychologist, 4, 23-32.

Côté, J., Salmela, J. H., Baria, A., \& Russell, S. J. (1993). Organizing and interpreting unstructured qualitative data. The Sport Psychologist, 7, 127-137.

Efklides, A. (2006). Metacognition and affect: What can metacognitive experiences tell us about the learning process? Educational Research Review, 1, 3-14. http://dx.doi.org/10.1016/j.edurev.2005.11.001

Efklides, A. (2014). How does metacognition contribute to the regulation of learning? An integrative approach. Psychological Topics, 23, 1-30.

Elo, S., \& Kyngäs, H. (2008). The qualitative content analysis process. Journal of Advanced Nursing, 62, 107-115. http://dx.doi.org/10.1111/j.1365-2648.2007.04569.x

Flavell, J. H. (1979). Metacognition and cognitive monitoring: A new area of cognitive developmental inquiry. American Psychologist, 34, 906-911.

Green, J., \& Thorogood, N. (2004). Analysing qualitative data. In: D. Silverman, D. (Ed.). Qualitative Methods for Health Research (pp. 173-200). London: Sage Publications.

Hasse, L., Thom, N. J., Shukla, A., Davenport, P. W., Simmons, A. N., Paulus, M. P., \& Johnson, D. C. (2014) Mindfulness-based training attenuates insula response to an aversive interoceptive challenge. Social Cognitive and Affective Neuroscience. Advance online publication. http://dx.doi.org/10.1093/scan/nsu042

Leventhal, H., \& Everhart, D. (1979). Emotion, pain, and physical illness. In C. E. Izard (Ed.). Emotions in personality and psychopathology (pp. 263-298). New York, NY: Plenum. 
1 MacIntyre, T., Igou, E. R., Moran, A., P., Campbell, M., \& Matthews, J. (2014). Metacognition and action: A new pathway to understanding social and cognitive aspects of expertise in sport. Frontiers in Psychology, 5, 1155. http://dx.doi.org/10.3389/fpsyg.2014.01155

MacIntyre, T. E., Moran, A. P., Collet, C., \& Guillot, A. (2013). An emerging paradigm: A strength-based approach to exploring mental imagery. Frontiers in Human Neuroscience, 7, 104. http://dx.doi.org/10.3389/fnhum.2013.00104

Mooneyham, B. W., \& Schooler, J. W. (2013). The cost and benefits of mind-wandering: A review. Canadian Journal of Experimental Psychology, 67, 11-18. http://dx.doi.org/10.1037/a0031569

Moran, A. P. (1996). The psychology of concentration in sport performers: A cognitive analysis. East Sussex: Psychology Press.

Moran, A. P. (2009). Cognitive psychology in sport: Progress and prospects. Psychology of Sport and Exercise, 10, 420-426. http://dx.doi.org/10.1016/j.psychsport.2009.02.010

Moran, A. P. (2012). Thinking in action: Some insights from cognitive sport psychology. Thinking Skills and Creativity, 7, 85-92. http://dx.doi.org/10.1016/j.tsc.2012.03.005

Nelson. T. O. (1996). Consciousness and metacognition. American Psychologist, 51, 102116.

Nietfeld, J. L. (2003). An examination of metacognitive strategy use and monitoring skills by competitive middle distance runners. Journal of Applied Sport Psychology, 15, 307320. http://dx.doi.org/10.1080/10413200390237942 
1 Randall, J. G., Oswald, F. L., \& Beier, M. E. (2014). Mind-wandering, cognition and performance: A theory-driven meta-analysis of attention regulation. Psychological Bulletin, 140, 1411-1431. http://dx.doi.org/10.1037/a0037428

Robinson, O. C. (2013). Sampling in interview-based qualitative research: A theoretical and practical guide. Qualitative Research in Psychology, 11, 25-41. http://dx.doi.org/10.1080/14780887.2013.801543

Rushall, B. S., \& Shewchuk, M. L. (1989). Effects of thought content instructions on swimming performance. Journal of Sports Medicine and Physical Fitness, 29, 326334.

Sarkar, M., \& Fletcher, D. (2014). Ordinary magic, extraordinary performance: Psychological resilience and thriving in high achievers. Sport, Exercise and Performance Psychology, 3, 46-60. http://dx.doi.org/10.1037/spy0000003

Schücker, L., Knopf, C., Strauss, B., \& Hagemann, N. (2014). An internal focus of attention is not always as bad as its reputation: How specific aspects of internally focused attention do not hinder running efficiency. Journal of Sport and Exercise Psychology, 36, 223-243. http://dx.doi.org/10.1123/jsep.2013-0200

Setanni, M., Magistro, D., \& Rabaglietti, E. (2012). Development and preliminary validation of an instrument to measure metacognition applied to physical activity during early adolescence. Cognition, Brain, Behaviour. An Interdisciplinary Journal, 16, 67-87.

Shea, N., Boldt, A., Bang, D., Yeung, N., Heyes, C., \& Frith, C. D. (2014). Supra-personal cognitive control and metacognition. Trends in Cognitive Sciences, 18, 186-193. http://dx.doi.org/10.1016/j.tics.2014.01.006 
1 Salmon, P., Hanneman, S., \& Harwood, B. (2010). Associative/dissociative cognitive strategies in sustained physical activity: Literature review and proposal for a mindfulness-based conceptual model. The Sport Psychologist, 24, 127-156.

Swann, C., Moran, A. P., \& Piggott, D. (2015). Defining elite athletes: Issues in the study of expert performance in sport psychology. Psychology of Sport and Exercise, 16, 3-14. http://dx.doi.org/10.1016/j.psychsport.2014.07.004

Tarricone, P. (2011). The taxonomy of metacognition. East Sussex: Psychology Press.

Tenenbaum, G. (2001). A social-cognitive perspective of perceived exertion and exertion tolerance. In R. N. Singer, H. Hausenblas, \& C. Janelle (Eds.). Handbook of sport psychology ( $2^{\text {nd }}$ ed.) (pp. 810-820). Hoboken, NJ: Wiley \& Sons.

Vaismoradi, M., Turunen, H., \& Bondas, T. (2013). Content analysis and thematic analysis: Implications for conducting a qualitative descriptive study. Nursing and Health Sciences, 15, 398-405. http://dx.doi.org/10.1111/nhs.12048

Wagstaff, C. R. D., Fletcher, D., \& Hanton, S. (2012). Exploring emotion abilities and regulation strategies in sport organizations. Sport, Exercise, and Performance Psychology, 1, 268-282. http://dx.doi.org/10.1037/a0028814

Williams, E. L., Jones, H. S., Sparks, A., Marchant, D. C., Midgley, A. W., \& McNaughton, L. R. (in press). Competitor presence reduces internal attentional focus and improves $16.1 \mathrm{~km}$ cycling time trial performance. Journal of Science and Medicine in Sport. http://dx.doi.org/10.1016/j.jsams.2014.07.003

Yoshida, T., Nakamura, T., Kubo, C., Molton, I. R., Jensen, M. P., Arimura, T., \& Hosoi, M. (2012). Cognitions, metacognitions, and chronic pain. Rehabilitation Psychology, 57, 207-213. http://dx.doi.org/10.1037/a0028903 
Table 1. Demographic variables of study sample $(n=10)$

\begin{tabular}{ll}
\hline Demographic Variables & \\
\hline Age & Mean: 35.6 \pm 6.6 years \\
Gender & 6 females, 4 males \\
Primary running event & Ultra-Distance $(n=2)$ \\
& $\begin{array}{l}\text { 10km - Marathon }(n=6) \\
3 \mathrm{~km}-10 \mathrm{~km}(n=2)\end{array}$ \\
& Olympic Games $(n=2)$ \\
$\begin{array}{l}\text { Athlete's highest standard } \\
\text { of performance }\end{array}$ & World championship level $(n=4)$ \\
& $\begin{array}{l}\text { European championship level }(n=3) \\
\text { Commonwealth Games }(n=1)\end{array}$ \\
Success at the athlete's & Infrequent success at international level $(n=3)$ \\
highest level & National titles, selected to represent nation $(n=4)$ \\
& Competitive at national level, selected to represent nation $(n=3)$
\end{tabular}




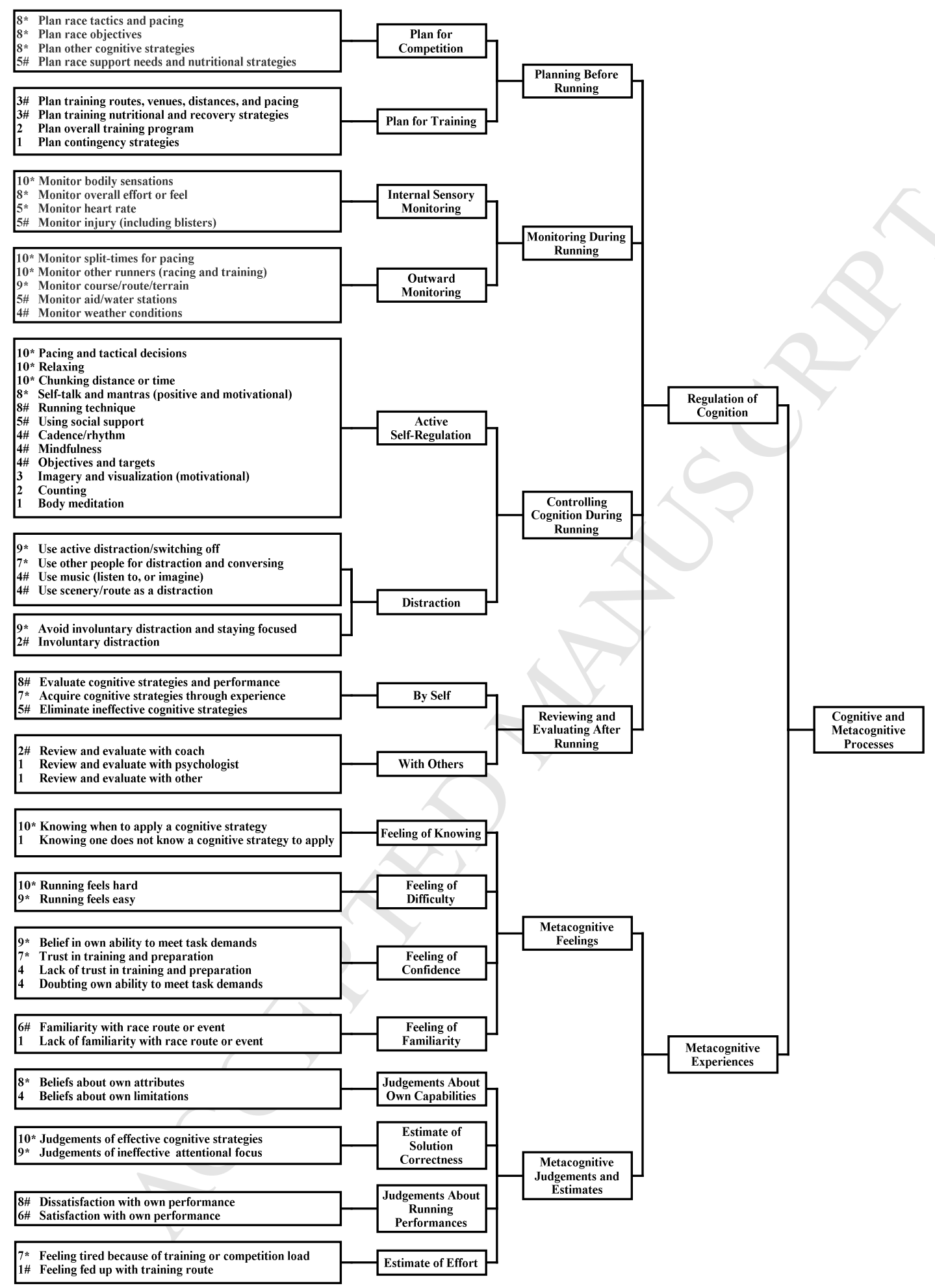

Figure 1. Cognitive and metacognitive processes in the regulation of performance and control of cognition by elite endurance runners. A frequency analysis is presented in the first column to indicate the number of participants mentioning each subcategory. Symbols denote either both $(*)$ or one (\#) of the successful elite athletes reported the cognitive/metacognitive process 


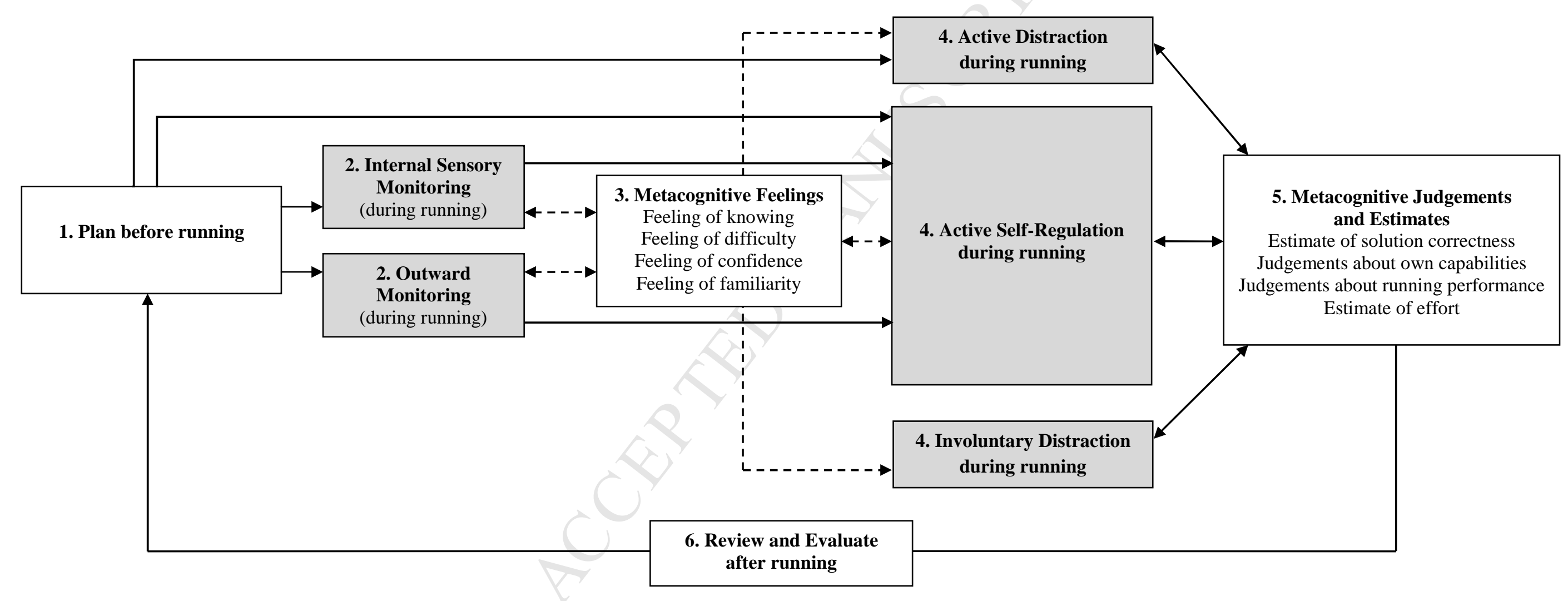

Figure 2. A metacognitive framework of attentional focus and cognitive control in elite endurance runners. 


\section{Highlights}

Applied a metacognitive approach to study attentional focus during endurance activity Interviewed ten elite endurance runners about cognitive strategy use during running A content analysis was used to interpret the data Findings indicate metacognitive activity influences cognitive control during running We present an integrative framework of metacognitive processes and attentional focus 


\title{
Metacognitive strategies in the self-regulation of performance in elite endurance runners.
}

\author{
Pre-Interview Information
}

\section{Outline of the study and the interview process}

This information sheet is to provide you with a little more insight into the interview we will be completing, and what I will be asking you to discuss. The interviews are part of a study I am undertaking on the mental strategies used by elite runners during endurance activity. The interview will involve thinking about past events and situations where you have employed various mental strategies. Mental strategies might include things you think about during competitive running, or during running training. An example of one such mental strategy is that used by Paula Radcliffe. In her book How to Run, she reveals how she counts to 100 to determine where she is during each mile. She explains: 'This is something that I started doing a long time ago as a means of focusing on where I was within each grass/road rep that was run to time rather than marked distance. I found it helped me to judge and pace myself. As I moved to road races, I learned that breaking each mile down worked well for me. For a half to full marathon pace, counting three times to 100 roughly equates to a mile: this technique helps me focus on where I am within each mile of the race and has become my technique for anchoring my concentration. I use it to truly stay in the moment.' This is just one example of a mental strategy during running. You may use many others and use them in your own way.

During the interview, I will ask you to talk about the mental strategies you use. We will discuss the mental strategies you use during competitive events, and also during running training. It is important to note that we will only discuss mental strategies during running, and not other types of training or event. I will ask you about how you monitor the mental strategies you use. For example, how do you know if a mental strategy is working effectively? Finally, I will also ask you about how you acquired the strategies you use, and how you have developed and refined your mental strategies over the course of your career.

This interview will be digitally recorded. This recording will be used to accurately capture and transcribe the interview. The written transcript of the interview will be sent to you within one week of this interview. At that stage you can check the written transcript for accuracy. You may also wish to add further detail or clarification to the interview at this point. The recordings and transcript will only be accessed by me and two principal investigators in this research study, and all information will be kept strictly confidential. Insights gathered from you and other participants may be used in writing a research paper which will be published in a reputable, peer reviewed journal. Though direct quotes from you 
may be used in the paper, your name and any other identifying information will be kept strictly anonymous.

The outcomes of this study may be used in many ways. The research might help you to analyse the mental strategies you currently use and gain a better insight into your own mental processes. The findings may also be beneficial to sport psychologists, coaches and athletes by employing the knowledge gained through this study to improve the performance of athletes in the early stages of their development, or individuals who experience difficulty coping with the demands of endurance activity. Finally, the findings of the study might also help researchers to better understand and categorise the thoughts and mental strategies elite endurance runners use during endurance performance.

Your participation in this study is entirely voluntary. Before the interview begins, I will ask you to sign an Informed Consent Form, demonstrating your understanding of the study and what is involved. However, you can choose not to consent, or to withdraw consent and stop participating in the study at any time. In the event you do choose to withdraw, all information you provide will be permanently destroyed and omitted from the final research paper. You may also choose to abstain from answering any questions within this interview. You may do so by answering 'no comment', and I will move on with the next question. If at any stage during the investigation you have any queries, you are encouraged to ask questions or raise concerns at any time about the nature of the study or the methods I am using.

Because I will be asking you to think back over past events, you may not be able to recall your mental strategy use straight away. Please take your time and don't worry about pausing to think during the interview. As I will also be asking you to recall your mental strategy use in both training, and in competitive events, again, please take your time to accurately recall your mental strategy use in each. Finally, at various stages during the interview I will be asking you to rate on a scale how frequently you use various mental strategies, or how effective you find various mental strategies. Again, take your time to carefully consider your responses to each.

If at any point I ask a question that you do not understand, please ask me to clarify and explain further. Thank you once again for your participation in this study and I look forward to meeting with you next week. 
Metacognitive strategies in the self-regulation of performance in elite endurance runners interview guide.

\section{Participant Number:}

Name:

Age:

Gender:

Address:

Telephone:

Email:

Main event:

Years running competitively:

International representation:

Year of first international representation:

Major Achievements:

Interview date:

Interview start time:

Interview finish time:

Duration of interview 


\section{Metacognitive strategies in the self-regulation of performance in elite endurance runners interview guide.}

\section{Part one - Outline of the study and the interview process (Not digitally recorded)}

Hi. I am conducting interviews on the mental strategies used by elite runners during endurance activity. The interview will involve thinking about past events and situations where you have employed various mental strategies. Mental strategies might include things you think about during competitive running, or during training. An example of one such mental strategy is that used by Paula Radcliffe. In her book How to Run, she reveals how she counts to 100 to determine where she is during each mile. She explains: 'This is something that I started doing a long time ago as a means of focusing on where I was within each grass/road rep that was run to time rather than marked distance. I found it helped me to judge and pace myself. As I moved to road races, I learned that breaking each mile down worked well for me. For a half to full marathon pace, counting three times to 100 roughly equates to a mile: this technique helps me focus on where I am within each mile of the race and has become my technique for anchoring my concentration. I use it to truly stay in the moment.' This is just one example of a mental strategy during running. You may use many others and use them in your own way.

During the interview, I will ask you to talk about the mental strategies you use. We will discuss the mental strategies you use during competitive events, and during running training. It is important to note that we will only discuss mental strategies during running, and not other types of training or event. I will ask you about how you monitor the mental strategies you use. For example, how do you know if a mental strategy is working effectively? Finally, I will also ask you about how you acquired the strategies you use, and how you have developed and refined your mental strategies over the course of your career.

This interview will be digitally recorded. This recording will be used to accurately capture and transcribe the interview. The written transcript of the interview will be sent to you within one week of this interview. At that stage you can check the written transcript for accuracy. You may also wish to add further detail or clarification to the interview at this point. The recordings and transcript will only be accessed by me and two principal investigators in this research study, and all information will be kept strictly confidential. Insights gathered from you and other participants may be used in writing a research paper which will be published in a reputable, peer reviewed journal. Though direct quotes from you may be used in the paper, your name and any other identifying information will be kept strictly anonymous.

The outcomes of this study may be used in many ways. The research might help you to analyse the mental strategies you currently use and gain a better insight into your own 
mental processes. The findings may also be beneficial to sport psychologists, coaches and athletes by employing the knowledge gained through this study to improve the performance of athletes in the early stages of their development, or individuals who experience difficulty coping with the demands of endurance activity. Finally, the findings of the study might also help researchers to better understand and categorise the thoughts and mental strategies elite endurance runners use during endurance performance.

Your participation in this study is entirely voluntary. Before the interview begins, I will ask you to sign an Informed Consent Form, demonstrating your understanding of the study and what is involved. However, you can choose not to consent, or to withdraw consent and stop participating in the study at any time. In the event you do choose to withdraw, all information you provide will be permanently destroyed and omitted from the final research paper. You may also choose to abstain from answering any questions within this interview. You may do so by answering 'no comment', and I will move on with the next question. If at any stage during the investigation you have any queries, you are encouraged to ask questions or raise concerns at any time about the nature of the study or the methods I am using.

Because I will be asking you to think back over past events, you may not be able to recall your mental strategy use straight away. Please take your time and don't worry about pausing to think during the interview. As I will also be asking you to recall your mental strategy use in both training, and in competitive events, again, please take your time to accurately recall your mental strategy use in each. Finally, at various stages during the interview I will be asking you to rate on a scale how frequently you use various mental strategies, or how effective you find various mental strategies. Again, take your time to carefully consider your responses to each.

If at any point I ask a question that you do not understand, please ask me to clarify and explain further. Thank you once again for your participation in this study. Are you happy with everything I've explained so far? If so, could I ask you to give your written informed consent to take part in this study (see informed consent sheet), and we will begin the interview. 


\section{Part Two - The interview (Digitally recorded)}

\section{Section One - General Questions}

We will start with some general questions about your running career to date and general mental preparation for running.

- Could you please tell me briefly about your running history and your achievements to date?

- Probe: When did you first start running?

- Probe: What international events have you competed in as a senior athlete?

- Does mental preparation play an important role in your running? If yes, could you tell me briefly about your general mental preparation for running?

- Prompt: General mental preparation, not specifically mental strategies.

- Prompt: Do you practice imagery/goal setting/relaxation, etc.?

In my study I am investigating the mental strategies experienced, elite endurance runners use during performance.

- For you - what do you understand by mental strategies during running?

- Do you use mental strategies during running? If yes, what mental strategies do you use? 


\section{$\underline{\text { Section Two }}$ - Specific questions on mental strategy use during running}

I am now going to focus a little more specifically on your mental strategy use during running.

- Did you use any mental strategies in your most recent running event? If yes, could you tell me about the mental strategies you used?

- Prompt: Starting with the beginning of the event, right through to completion.

- Probe: What mental strategy did you use at stage X of the event?

- Could you describe the mental strategies you have used in running events prior to that?

- Prompt: Not the very beginning of your career, but thinking back a number of years.

- Probe: $\underline{\text { How }}$ were your mental strategies different then, compared with now?

- Could you describe the mental strategies you would have used at the very beginning of your running career (i.e., when you first started running)?

○ Probe: $\underline{\text { How }}$ were your mental strategies different then, compared with now?

Thank you. I will return to some of the points you've mentioned later in the interview. For now, could you please read the following list of mental strategies typically used by runners.

[Hand List 1 to the participant]

- Do you use any of the mental strategies listed here? If yes, could you elaborate on how you use each of those mental strategies? Please use specific examples where possible.

- Prompt: How do you focus on pacing, compartmentalise distanceltime, etc.?

- Do the mental strategies you use affect your performance in any way? If yes, could you tell me how the mental strategies you use affect your performance?

- Prompt (only if required): What about pacing, or feelings of effort?

- Probe: Is your performance noticeably different when you use/don't use those mental strategies? 


\section{Section Three - Specific questions on mental strategy use during competitive running:}

I am now going to focus on the mental strategies you use during competitive running events.

- Do you use different mental strategies during different competitive running events?

- Prompt: For example, during a short race v's a long race, or a road/trail/track race.

- Probe: Why do you use different mental strategies in different competitive events?

- Probe: Do the mental strategies you use change over the course of a season?

- Could you tell me how you choose a mental strategy to use during competitive running?

- Probe: Do you consciously decide on mental strategies to use?

- Probe: Do you use different mental strategies at different times in the same event?

- Probe: Do you plan beforehand mental strategies to use during competitive running?

- Probe: Do you choose a mental strategy to use in reaction to events that happen during competitive running?

- Are there other situational factors, apart from those you've just discussed, which affect your mental strategy use during competitive running? If yes, could you tell me about any that come to mind? Please give specific situations/examples where possible.

- Prompts: Competitors, terrain, conditions, weather, event importance, stage of race.

- Probe: Have you tried different mental strategies in those situations before?

- Are there other mental strategies you would use during competitive running that are not listed here (see list 1)? If yes, please tell me about them, giving specific examples.

Could you now please rate each of the following types of mental strategy in terms of how frequently you use each category during competitive running? If you also use other mental strategies during competitive running, please include these at the end of the list.

[Hand Rating Scale 1 to the participant]

Ratings are based on a 1-5 scale where: $1=\underline{\text { Never }} ; 2=\underline{\text { Rarely }} ; 3=\underline{\text { Sometimes }} ; 4=\underline{\text { Often }} ; 5$ $=\underline{\text { Almost always }}$ 


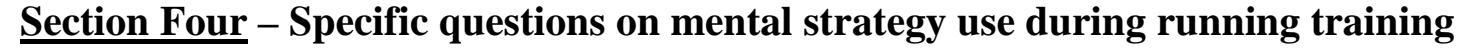

I am now going to focus on the mental strategies you use during running training.

- Do you use different mental strategies during different types of running training session?

- Prompt: Intervals, Tempo, Long distance, or easy recovery training runs.

- Probe: Why do you use different mental strategies in different training sessions?

- Probe: Do the mental strategies you use in training change in the lead up to competition?

- Could you tell me how you choose a mental strategy to use during running training?

- Probe: Do you consciously decide on mental strategies to use?

- Probe: Do you use different mental strategies at different times in the same session?

- Probe: Do you plan beforehand mental strategies to use during running training?

- Probe: Do you choose a mental strategy to use in reaction to events that happen during running training?

- Are there other situational factors, apart from those you've just discussed, which affect your mental strategy use during running training? If yes, could you tell me about any that come to mind? Please give specific situations/examples where possible.

- Prompt: Intensity of session, terrain, conditions, weather, proximity to competition.

- Probe: Have you tried different mental strategies in those situations before?

- Are there other mental strategies you would use during running training that are not listed here (see list 1)? If yes, please tell me about them, giving specific examples.

Could you now please rate each of the following types of mental strategy in terms of how frequently you use each category during running training? If you also use other mental strategies during running training, please include these at the end of the list.

[Hand Rating Scale 2 to the participant]

Ratings are based on a 1-5 scale where: $1=\underline{\text { Never }} ; 2=\underline{\text { Rarely }} ; 3=\underline{\text { Sometimes }} ; 4=\underline{\text { Often }} ; 5$ $=\underline{\text { Almost always }}$ 


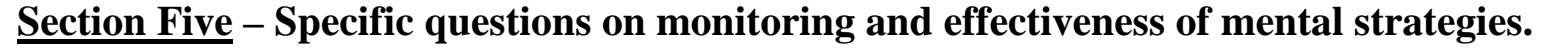

I am now going to ask you about how you monitor the effectiveness of the various mental strategies you use. For example, I am interested in finding out about how you know if a mental strategy is working for you, or not.

- Do you monitor the effectiveness of the mental strategies you use? If yes, could you tell me how you do this?

- Prompt (only if required): For example, monitor pacelfeelings of exertion, etc.

- Probe: How do you know a mental strategy is working for you?

- Probe: Do you monitor throughout the run - to completion?

- Probe: Do you evaluate your mental strategies post-run (competition and training)?

- For you, do different mental strategies have different performance effects? If yes, please elaborate on how you feel different mental strategies affect your performance.

- Probe: Do you use this knowledge to choose a mental strategy to use?

- Do you change or modify a mental strategy if one is not working? If yes, could you tell me how do you do this? Please give specific examples where possible.

- Probe: How do you know a mental strategy is not working for you?

- Probe: Do you consciously make a decision to modify the mental strategy used?

- Are there any other aspects to how you monitor the effectiveness of your mental strategies that we have not discussed here?

Could you now please rate each of the following types of mental strategy in terms of how effective you find each category during competitive running or training? If you also use other mental strategies during running, please include these at the end of the list and rate each.

[Hand Rating Scale 3 to the participant]

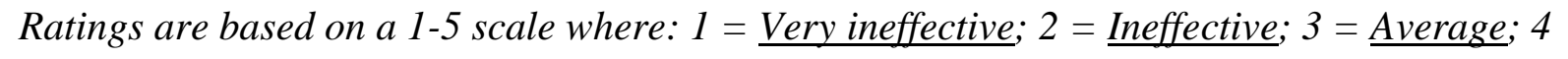
$=\underline{\text { Effective }} ; 5=\underline{\text { Very effective }}$ 


\section{Section Six - Specific questions on the acquisition, development and refinement of the mental strategies used.}

In this final section, I'm going to probe a little more into how you acquired, developed, and refined the mental strategies you use. We discussed in Section 2 how your mental strategy use has changed during your career - I would now like to delve deeper into this.

- How did you acquire the mental strategies you use?

- Probe: Why did you acquire those mental strategies?

- Probe: When did you acquire those mental strategies?

- Have you attempted to develop and refine the mental strategies you use? If yes, could you tell me how you have done this? Please give specific examples where possible.

- Probe: If you haven't developed or refined your mental strategies, thinking about it now, how might you develop or refine those mental strategies?

- Probe: Why did you develop and refine your mental strategies?

- Are there mental strategies you have tried before that didn't work? If yes, what were they?

- Probe: How did you know that mental strategy was not working for you?

- Probe: Did you decide to change that mental strategy? If yes, what did you change?

Could you now please tick to indicate which of the following methods you have used to acquire, and secondly to develop and refine the mental strategies you use during running. You may wish to make some additional comments to clarify if necessary.

[Hand List 2 to the participant]

- Do you consider your mental strategy use a strength, or a weakness? Please elaborate.

- Probe: What else do you consider as your main strengths/weaknesses as a runner?

- Are there any other aspects to how you acquired, developed and refined your mental strategies that we have not discussed here? If yes, please tell me about them. 


\section{ACCEPTED MANUSCRIPT}

\section{Conclusion to the interview}

- Are there any other mental strategies or aspects of attentional focus you would like to discuss that we have not covered in the interview?

Concluding remarks and questions on the interview

- How do you think this interview went?

- Do you feel we fully explored your mental strategy use during running?

- Did I lead or influence your responses in any way?

- Have you any comments or suggestions about the interview itself?

Thank you for taking the time to complete this interview. Your comments and experiences will be of great value in my study and will contribute to the overall success of this project.

Do you have any further points you would like to add to this discussion, or any questions you would like to ask at this point?

In the next week I will send you a copy of the transcript for this interview. I would ask you to read through it to ensure it is an entirely accurate record of everything we have discussed today. If you wish to further add to any of your comments, or further clarify anything, please feel free to do so at this stage.

Again, I would like to assure you that all comments raised will be treated with the strictest confidentiality and no individual contributor will be referred to by name in the discussion and presentation of the results of this interview. Thank you for your time, comments, and interest in this research.

[Conclusion to the interview. Stop digital recorder.] 